\title{
ANTIMICROBIAL PROPERTIES IN BARK AND LEAF EXTRACTS OF FOUR CINNAMOMUM SPECIES
}

\author{
Shimna Keloth1, Kuntagod Subraya Krishnamurthy², Jiju Janardhanan³, Shamina Azeez ${ }^{4}$ \\ ${ }_{1}^{1}$ Research Scholar, Division of Crop Production and PHT, ICAR-Indian Institute of Spices Research, Kozhikode, Kerala. \\ 2Principal Scientist, Division of Crop Production and PHT, ICAR-Indian Institute of Spices Research, Kozhikode, Kerala. \\ ${ }^{3}$ Associate Professor, Department of Microbiology, Co-operative Institute of Health Sciences, Thalassery, Kerala. \\ ${ }^{4}$ Principal Scientist, Biochemistry, Division of Post Harvest Technology and Agricultural Engineering, ICAR-Indian Institute of \\ Horticultural Research, Bengaluru.
}

\section{BACKGROUND}

ABSTRACT

Cinnamon has been recognised for its flavouring and medicinal properties since ancient times and is the second most important spice sold in the world market. The antibacterial activities of hexane, chloroform, methanol and water extracts of four Cinnamomum species were studied.

\section{MATERIALS AND METHODS}

Both bark and leaf extracts of C. verum, C. cassia, C. tamala and C. camphora was tested in vitro against 12 bacterial species by agar well diffusion assay and minimum inhibitory concentration (MIC) was determined. The bacterial species used in the study was Listeria monocytogenes, Vibrio cholerae, Escherichia coli ATCC 25922, Klebsiella pneumoniae ATCC 700603, Staphylococcus aureus ATCC 29213, Salmonella paratyphi, Salmonella typhi, Proteus mirabilis, Shigella boydii, Stenotrophomonas maltophilia ATCC 17666, Enterobacter hormaechei and Pseudomonas aeruginosa ATCC 27853.

\section{RESULTS}

The present study indicated that both bark and leaf extracts have the ability to inhibit Gram-positive and Gram-negative organisms. But bark extracts were more effective than leaf extracts in inhibiting the organisms. S. maltophilia was inhibited by all the tested bark extracts except methanol extracts of C. cassia and C. camphora. The diameter of zone of inhibition ranged from 16$51 \mathrm{~mm}$. C. camphora hexane extracts showed least MIC value of $3.13 \mathrm{mg} / \mathrm{mL}$ with S. maltophilia. V. cholerae a potent pathogen was inhibited by C. camphora leaf chloroform extract at the MIC of $3.13 \mathrm{mg} / \mathrm{mL}$.

\section{CONCLUSION}

From the present study, it could be concluded that selected extracts of cinnamon species have a remarkable potential in inhibiting the growth of major pathogenic bacteria.

\section{KEYWORDS}

Cinnamomum Species, Minimum Inhibitory Concentration, Agar Well Diffusion Assay.

HOW TO CITE THIS ARTICLE: Keloth S, Krishnamurthy KS, Janardhanan J, et al. Antimicrobial properties in bark and leaf extracts of four cinnamomum species. J. Evolution Med. Dent. Sci. 2018;7(05):683-689, DOI: 10.14260/jemds/2018/155

\section{BACKGROUND}

The need of exploring new methods of food preservation for the partial and total replacement of antimicrobial chemical additives are increasing nowadays. The new method of food preservation called 'natural antimicrobial system' was coined by Gould in 1995. His study emphasised the possible use of spices and their derivatives as an alternative for chemical antimicrobial food additives. Natural additives are safe, enhance flavour and they do not have any side effects. ${ }^{1}$ Cinnamon has been recognised for its flavouring and medicinal properties since ancient times and is the second most important spice sold in the world market. Some economically important species of Cinnamomum are C. verum (Ceylon cinnamon naturally occurring in Sri Lanka, Southern India and Myanmar cultivated mainly for quills and

'Financial or Other Competing Interest': None.

Submission 27-11-2017, Peer Review 14-01-2018,

Acceptance 20-01-2018, Published 29-01-2018.

Corresponding Author:

Shimna Keloth

Division of Crop Production and PHT,

ICAR- Indian Institute of Spices Research,

Kozhikode-673012, Kerala.

E-mail: shimna4@gmail.com

DOI: $10.14260 /$ jemds $/ 2018 / 155$

(c) (i) $\$$ bark oil, C. cassia (Chinese cassia occurring in South China, Vietnam, Laos and Myanmar cultivated for bark and leaf oil), C. tamala (the Indian cassia distributed in the forests of North Eastern India and Myanmar whose leaves are used in flavouring dishes), C. camphora (camphor tree, cultivated in Japan, Taiwan, China, Vietnam and Thailand, cultivated for camphor and camphor oil). ${ }^{2}$ It was found that Cinnamon oil has marked antimicrobial activity against Escherichia coli, Staphylococcus aureus and Candida albicans. ${ }^{3}$ Transcinnamaldehyde was observed as the major volatile compound in cinnamon and cassia bark oils. Brackman et al (2008) reported that cinnamaldehyde and cinnamaldehyde derivatives reduce virulence in Vibrio spp. ${ }^{4}$ These compounds can interfere with biofilm formation, stress response and virulence in Vibrio spp. It possesses potent antibacterial, antifungal, antitermitic, larvicidal, nematicidal and insecticidal properties. ${ }^{5}$ Camphor was found to be present at highest percentage in C. camphora bark and leaf essential oil. Methanol extracts of leaves and branches of C. camphora extracts were found to be effective in inhibiting Grampositive bacteria such as Bacillus cereus, Bacillus subtilis and S. aureus. 6 Antibacterial activity of extracts of cinnamon essential oil was proved by different studies.

Though there are a few reports available on antibacterial activity of solvent extracts of some cinnamon species, studies 
on comparison among different Cinnamomum species is very less and hardly there are any studies on leaf extracts. The main objective of the present study was to compare antibacterial properties of four Cinnamomum species in both bark as well as leaf extracts and to determine minimum inhibitory concentration (MIC) of extracts to inhibit the bacteria and compare the antimicrobial potential of extracts with standard antibiotics.

\section{MATERIALS AND METHODS}

In-Vitro study was conducted to compare antibacterial properties of four Cinnamomum species in both bark as well as leaf extracts and to determine MIC of extracts to inhibit the bacteria and compare the antimicrobial potential of extracts with standard antibiotics.

\section{Plant Materials}

Bark and leaf samples of 4 cinnamon species were collected from ICAR-IISR experimental farms, Peruvannamuzhi and Chelavoor, Kozhikode, Kerala. The cinnamon species used for the studies were C. verum, C. cassia, C. tamala and C. camphora.

\section{Reagents and Materials}

Solvents such as hexane, chloroform, methanol, and dimethyl sulfoxide (DMSO) were supplied by Sisco Research Laboratory Ltd. (SRL). Mueller-Hinton agar and antibiotic discs such as IC 005, IC 002, IC 003, HX 027, HX 063 and HX 001 were supplied by Hi-Media.

\section{Microorganisms and Culture}

A total of 12 bacteria were kindly provided by the Department of Molecular Biology and Diagnostics, Malabar Institute of Medical Sciences, Kozhikode, Kerala. They are Listeria monocytogenes, Vibrio cholerae, Escherichia coli ATCC 25922, Klebsiella pneumoniae ATCC 700603, Staphylococcus aureus ATCC 29213, Salmonella paratyphi, Salmonella typhi, Proteus mirabilis, Shigella boydii, Stenotrophomonas maltophilia ATCC 17666, Enterobacter hormaechei, Pseudomonas aeruginosa ATCC 27853. The strains were preserved as stock culture on nutrient agar.

\section{Preparation of Crude Extract}

Cinnamon samples (leaf and bark) collected from the farm were thoroughly cleaned, dried in an oven (Memmert make) at $45^{\circ} \mathrm{C}$ to a constant weight and then powdered. Powdered samples were extracted with solvents in the order of increasing polarity such as hexane, chloroform, methanol and water. The filtrates were vapourised by Rotavap (Buchi, Germany) and dried. The extracts were dissolved in DMSO to the final concentration of $25 \mathrm{mg} / \mathrm{mL}$ and stored at $40^{\circ} \mathrm{C}$ until further use.

\section{Determination of Antibacterial Activity}

Antibacterial activity of cinnamon extracts was determined by agar well-diffusion method.7 The bacterial samples were taken from stock culture and suspended in sterile nutrient broth at a density equivalent to that of 0.5 McFarland standards. The tubes were kept for incubation at $37^{\circ} \mathrm{C}$ for 4 hours. Sterile Mueller-Hinton agar plates were prepared. A sterile cotton swab was dipped into the standardised bacterial suspension and used to evenly inoculate the entire surface of Mueller-Hinton agar plates. Wells of $8 \mathrm{~mm}$ diameter were cut on the agar surface. $100 \mu \mathrm{L}$ of extracts (dissolved in DMSO, $25 \mathrm{mg} / \mathrm{mL}$ ) were added to the well. A well-containing $100 \mu \mathrm{L}$ DMSO alone has served as control. The inoculated plates were incubated overnight at $37^{\circ} \mathrm{C}$. After incubation, diameter of zone of inhibition were measured and recorded in $\mathrm{mm}$.

\section{Determination of Minimum Inhibitory Concentration (MIC)}

The combination of extract and bacteria showing good zone of inhibition was selected for determination of minimum inhibitory concentration. A stock solution of extract at a concentration of $25 \mathrm{mg} / \mathrm{mL}$ was prepared. $0.5 \mathrm{~mL}$ of extract was mixed with $0.5 \mathrm{~mL}$ of nutrient broth in a test tube. The tubes were mixed well and $0.5 \mathrm{~mL}$ of extract with nutrient broth were taken from the tube and mixed with another test tube with $0.5 \mathrm{~mL}$ nutrient broth, and the serial dilution continued to get a final concentration of $1.56 \mathrm{mg} / \mathrm{mL}$ in the last test tube. $0.5 \mathrm{~mL}$ of the standardised bacterial suspension was inoculated to all the test tubes and incubated overnight at $37^{\circ} \mathrm{C}$. After incubation a sterile cotton swab was dipped into the test tubes containing extracts and bacterial suspension, and used to evenly inoculate the entire surface of Mueller-Hinton agar plates. The plates were again incubated overnight. The MHA plates showing lowest and highest bacterial density were selected. The plate having bacterial density adjacent to the highest density was considered for determination of MIC.

\section{Comparison of Antibacterial Potential of Extracts with Antibiotics}

Combination of antibiotics specific for Gram positive, Gram negative and Pseudomonas species were used for testing. Sterile MHA plates were swabbed with standardised bacterial suspension and antibiotic rings were placed on the agar surface using sterile forceps and incubated overnight at $37^{\circ} \mathrm{C}$. The diameter of zone of inhibition in $\mathrm{mm}$ was measured and recorded. The concentrations of each antibiotic with the concentration of extracts were analysed by comparing diameter of zone of inhibition of both extract and antibiotic for a specific organism by paired t-test. 


\begin{tabular}{|c|c|c|c|c|c|c|c|c|c|c|c|c|}
\hline 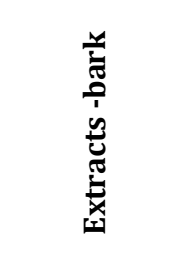 & 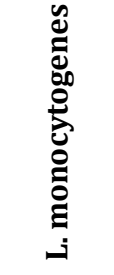 & $\begin{array}{l}0 \\
\frac{\pi}{0} \\
\frac{\pi}{0} \\
\frac{\partial}{0} \\
>\end{array}$ & $\begin{array}{l}\text { : } \\
\text { 뭉 }\end{array}$ & 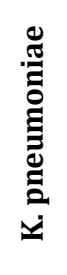 & 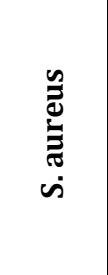 & 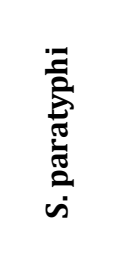 & $\underset{\dot{s}}{\vec{z}}$ & 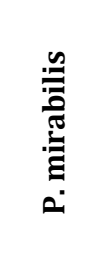 & 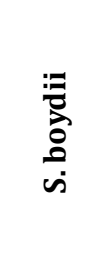 & 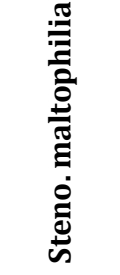 & 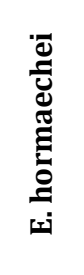 & 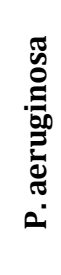 \\
\hline \multicolumn{13}{|l|}{ C. verum } \\
\hline hexane & 21 & 30 & 20 & 15 & 28 & 24 & 24 & 27 & 24 & 41 & 18 & 20 \\
\hline chloroform & ND & ND & ND & ND & ND & ND & ND & ND & ND & 21 & 13 & ND \\
\hline methanol & 11 & ND & ND & ND & ND & ND & ND & ND & ND & 25 & ND & 22 \\
\hline water & 12.5 & ND & ND & ND & ND & ND & ND & 14 & ND & 16.5 & 13 & 14 \\
\hline \multicolumn{13}{|l|}{ C. cassia } \\
\hline hexane & 26 & 28 & 25 & 19 & 17 & 22 & 25 & 29 & 26 & 51 & ND & 21 \\
\hline chloroform & 17 & 18 & 13 & 13 & ND & 19 & 15 & 13 & ND & 35 & 12 & 19 \\
\hline methanol & 10 & ND & ND & ND & ND & ND & ND & ND & ND & ND & ND & 17 \\
\hline water & 12 & 13 & ND & ND & 12 & 13 & ND & 16 & ND & 13 & 12.5 & 16 \\
\hline \multicolumn{13}{|l|}{ C. tamala } \\
\hline hexane & 14.5 & ND & 10 & ND & ND & 12 & 12 & 25 & 12 & 25 & ND & 14 \\
\hline chloroform & 11 & ND & 11 & ND & ND & 15 & ND & ND & 11 & 22 & ND & 30 \\
\hline methanol & ND & ND & ND & ND & ND & ND & ND & ND & ND & 25 & ND & ND \\
\hline water & 13 & ND & ND & ND & ND & 12.5 & ND & 13 & ND & 17 & 12 & 16 \\
\hline \multicolumn{13}{|l|}{ C. camphora } \\
\hline hexane & 11.5 & ND & 12 & ND & ND & 12 & 12 & 12 & 13 & 26 & ND & 22 \\
\hline chloroform & 20 & ND & ND & ND & ND & ND & ND & ND & 12 & 16 & ND & 16 \\
\hline methanol & 9 & ND & ND & ND & ND & ND & ND & ND & ND & ND & ND & 22 \\
\hline water & 12 & ND & ND & ND & ND & 12 & ND & 15 & ND & 13 & ND & ND \\
\hline DMSO control & No ZOI & No ZOI & No ZOI & 10 & No ZOI & No ZOI & No ZOI & No ZOI & No ZOI & No ZOI & 13 & 18 \\
\hline
\end{tabular}

- $\quad$ ND- not detected.

- NO ZOI- no zone of inhibition.

\begin{tabular}{|c|c|c|c|c|c|c|c|c|c|c|}
\hline $\begin{array}{c}\text { Extracts - } \\
\text { leaf }\end{array}$ & $\begin{array}{c}\mathrm{L} . \\
\text { monocytogenes }\end{array}$ & $\begin{array}{c}\mathrm{V} . \\
\text { cholerae }\end{array}$ & $\begin{array}{c}\text { E. } \\
\text { coli }\end{array}$ & $\begin{array}{c}\mathrm{K} . \\
\text { pneumoniae }\end{array}$ & $\begin{array}{c}\text { S. } \\
\text { aureus }\end{array}$ & $\begin{array}{c}\text { S. } \\
\text { paratyphi }\end{array}$ & $\begin{array}{c}\text { S. } \\
\text { typhi }\end{array}$ & $\begin{array}{c}\text { P. } \\
\text { mirabilis }\end{array}$ & $\begin{array}{c}\text { S. } \\
\text { boydii }\end{array}$ & $\begin{array}{c}\text { Steno. } \\
\text { maltophilia }\end{array}$ \\
\hline \multicolumn{11}{|l|}{ C. verum } \\
\hline Hexane & 16 & ND & 12 & 12.5 & 13 & 17 & 14 & 14.5 & 11.5 & 20 \\
\hline chloroform & 15.5 & ND & 14 & 12 & 15 & 15 & 13 & 14 & ND & 26 \\
\hline methanol & 12 & 12 & 15 & 12 & 13 & 15 & 13 & ND & ND & 16 \\
\hline Water & 12 & 13 & ND & ND & ND & 12 & ND & 16 & 12.5 & 15 \\
\hline \multicolumn{11}{|l|}{ C. cassia } \\
\hline Hexane & 21 & 12 & 13 & 15 & 14 & 16 & 11.5 & 14 & 13 & 24 \\
\hline chloroform & 14 & 12.5 & 13 & 13 & 15 & 17 & 15 & 16 & 16 & 29 \\
\hline methanol & 12 & 12 & 12 & 12 & ND & 13 & ND & ND & ND & 19 \\
\hline Water & 12 & 14 & ND & ND & 14 & 13.5 & ND & 17 & ND & 16 \\
\hline \multicolumn{11}{|l|}{ C. tamala } \\
\hline Hexane & ND & 29 & 13 & 12 & ND & 13 & ND & ND & 11.5 & 20 \\
\hline chloroform & 12.5 & ND & ND & 13.5 & ND & ND & ND & ND & ND & 20 \\
\hline methanol & 12 & 13 & 12 & 13 & ND & ND & ND & ND & ND & 19 \\
\hline Water & 11.5 & ND & ND & ND & 12 & ND & 14 & 14 & ND & 14 \\
\hline \multicolumn{11}{|l|}{$\begin{array}{c}\text { C. } \\
\text { camphora }\end{array}$} \\
\hline Hexane & 14 & 30 & 14 & 13.5 & ND & ND & ND & ND & 13 & 21 \\
\hline chloroform & 12 & 31 & ND & 13 & ND & ND & ND & ND & ND & ND \\
\hline methanol & 12 & 19 & ND & ND & 12 & ND & ND & 12.5 & ND & ND \\
\hline water & ND & 12.5 & ND & 13 & 12 & 12 & ND & 15 & ND & 15 \\
\hline $\begin{array}{c}\text { DMSO } \\
\text { control }\end{array}$ & No ZOI & No ZOI & $\begin{array}{l}\text { No } \\
\text { ZOI }\end{array}$ & 10 & No ZOI & No ZOI & $\begin{array}{l}\text { No } \\
\text { ZOI }\end{array}$ & No ZOI & $\begin{array}{l}\text { No } \\
\text { ZOI }\end{array}$ & No ZOI \\
\hline \multicolumn{11}{|c|}{ Table 2. Diameter of Zone of Inhibition ( $\mathrm{mm}$ ) of Leaf Extract } \\
\hline
\end{tabular}




\begin{tabular}{|c|c|c|c|}
\hline Species & Extract & bacteria & MIC (mg/ml) \\
\hline \multirow[t]{2}{*}{ C. verum } & Hexane & $\begin{array}{l}\text { S. aureus } \\
\text { S. typhi } \\
\text { V. cholera } \\
\text { S. boydii } \\
\text { E. coli }\end{array}$ & $\begin{array}{l}6.25 \\
12.5 \\
6.25 \\
12.5 \\
12.5\end{array}$ \\
\hline & Methanol & P. aeruginosa & 12.5 \\
\hline \multirow[t]{2}{*}{ C. cassia } & Hexane & $\begin{array}{c}\text { S. typhi } \\
\text { S. boydii } \\
\text { S. maltophilia } \\
\text { E. coli }\end{array}$ & $\begin{array}{c}12.5 \\
12.5 \\
3.13 \\
25\end{array}$ \\
\hline & Chloroform & S. maltophilia & 12.5 \\
\hline \multirow{2}{*}{ C. tamala } & Chloroform & P. aeruginosa & 6.25 \\
\hline & Methanol & S. maltophilia & 12.5 \\
\hline \multirow{3}{*}{ C. camphora } & \multirow{2}{*}{ Hexane } & \multirow{2}{*}{ P. aeruginosa S. maltophilia } & 6.25 \\
\hline & & & 12.5 \\
\hline & Methanol & P. aeruginosa & 6.25 \\
\hline
\end{tabular}

\begin{tabular}{|c|c|c|c|}
\hline Species & Extract & Bacteria & MIC (mg/ml) \\
\hline \multirow{2}{*}{ C. verum } & \multirow{2}{*}{ Chloroform } & P. aeruginosa & 12.5 \\
\hline & & S. maltophilia & 6.25 \\
\hline \multirow{2}{*}{ C. cassia } & \multirow{2}{*}{ Chloroform } & S. paratyphi & 12.5 \\
\hline & & S. maltophilia & 6.25 \\
\hline C. tamala & Hexane & V. cholerae & 6.25 \\
\hline \multirow{2}{*}{ C. camphora } & Hexane & \multirow{2}{*}{ V. cholerae } & 6.25 \\
\hline & Chloroform & & 3.13 \\
\hline
\end{tabular}

\begin{tabular}{|c|c|c|c|c|c|c|c|c|c|c|c|c|c|c|c|c|c|c|c|c|}
\hline Bacteria & IPM & CIP & TOB & MO & OF & SPX & LE & NX & COT & CL & NA & AMC & $\mathbf{K}$ & GAT & GEN & AK & $\mathbf{S}$ & CTR & CPD & TI \\
\hline P. mirabilis & 30 & 27 & 33 & 29 & 30 & 25 & 35 & 33 & 27 & 16 & 20 & 22 & 31 & 22 & 25 & 24 & 30 & 33 & 30 & 35 \\
\hline S. boydii & 25 & 16 & 25 & 20 & 15 & 16 & 20 & 17 & ND & 12 & ND & 11 & 24 & 12.5 & 29 & 23 & 14 & 30 & 20 & 23 \\
\hline E. coli & 30 & 40 & 30 & 30 & 30 & 30 & 37 & 36 & 35 & 20 & 33 & ND & 30 & 35 & 29 & 22 & 27 & 37 & 22 & 35 \\
\hline $\begin{array}{c}\mathrm{K} . \\
\text { pneumoniae }\end{array}$ & 27 & 18 & 23 & 22 & 22 & 20 & 21 & 20 & 30 & ND & 19 & ND & 27 & 20 & 24 & 21 & 20 & 22 & 12 & ND \\
\hline V. cholerae & 25 & 26 & 36 & 29 & 29 & 32 & 27 & 30 & 12 & 20 & 18 & 29 & 25 & 24 & 32 & 22 & 30 & 32 & 21 & 30 \\
\hline S. typhi & 25 & 21 & 29 & 34 & 15 & 27 & 32 & 27 & 44 & ND & 19 & 22 & 30 & 28 & 29 & 20 & 20 & ND & 12 & 23 \\
\hline S. paratyphi & 29 & 16 & 31 & 20 & 20 & 21 & 25 & ND & 19 & 12 & SZ & SZ & 30 & 22 & 26 & 17 & 15 & 17 & 17 & 20 \\
\hline $\begin{array}{c}\text { E. } \\
\text { hormaechei }\end{array}$ & 32 & 33 & 25 & 31 & 12 & 31 & 29 & 25 & 35 & 15 & 24 & 12 & 25 & 30 & 24 & 24 & 22 & 25 & 14 & 30 \\
\hline $\begin{array}{c}\mathrm{P} . \\
\text { aeruginosa }\end{array}$ & & & & AT & & $\mathrm{AZ}$ & & & TCC & PIT & GAT & $\mathrm{CPZ}$ & NET & CB & & & MZ & & PI & \\
\hline & 33 & 28 & 35 & 26 & 14 & 38 & 28 & 29 & 27 & 27 & 26 & 23 & 28 & 26 & 23 & 25 & 32 & 25 & 26 & 21 \\
\hline
\end{tabular}

IPM-imipenem, CIP- ciprofloxacin, TOB- tobramycin, MO- moxifloxacin, OF- ofloxacin, SPX- sparfloxacin, LE- levofloxacin, NXnorfloxacin, COT- co-trimoxazole, CL- colistin, NA- nalidixic acid, AMC- augmentin, K- kanamycin, GAT- gatifloxacin, GENgentamicin, AK- amikacin, S- streptomycin, CTR- ceftriaxone, CPD- cefpodoxime, TI- ticarcillin, CB- carbenicillin, PI- piperacillin, AT- aztreonam, AZ- azlocillin, TCC- ticarcillin, PIT- piperacillin, GAT- gatifloxacin, CPZ- cefoperazone, NET- netillin, MZ- mezlocillin.

\begin{tabular}{|c|c|c|c|c|c|c|c|c|c|c|c|c|c|c|c|c|c|c|c|c|}
\hline Bacteria & CEP & CD & COT & $\mathbf{E}$ & GEN & OF & $\mathbf{P}$ & VA & AMP & C & $\mathbf{O X}$ & LZ & AZM & AK & CLR & TEI & MET & AMC & NV & TE \\
\hline S. aureus & 33 & 35 & 20 & 30 & 31 & 30 & 20 & 19 & 20 & 23 & 24 & 19 & 22 & 30 & 22 & 19 & 31 & 23 & 33 & 19 \\
\hline $\begin{array}{c}\text { L. } \\
\text { monocytogenes }\end{array}$ & ND & 21 & ND & 23 & 26 & 22 & ND & 20 & ND & 23 & ND & 20 & 20 & 29 & 21 & 22 & ND & ND & 21 & 21 \\
\hline S. maltophilia & \multicolumn{20}{|c|}{ Sensitive (ZOI > 35mm) } \\
\hline
\end{tabular}

CEP- cephalothin, CD- clindamycin, COT- Co-trimoxazole, E- erythromycin, GEN- gentamicin, OF- ofloxacin, P- penicillin, VAvancomycin, AMP- ampicillin, C- chloramphenicol, OX- oxacillin, LZ- linezolid, AZM- azithromycin, AK- amikacin, CLRclarithromycin, TEI- teicoplanin, MET- methicillin, AMC- amoxyclav, NV- novobiocin, TE- tetracycline. 

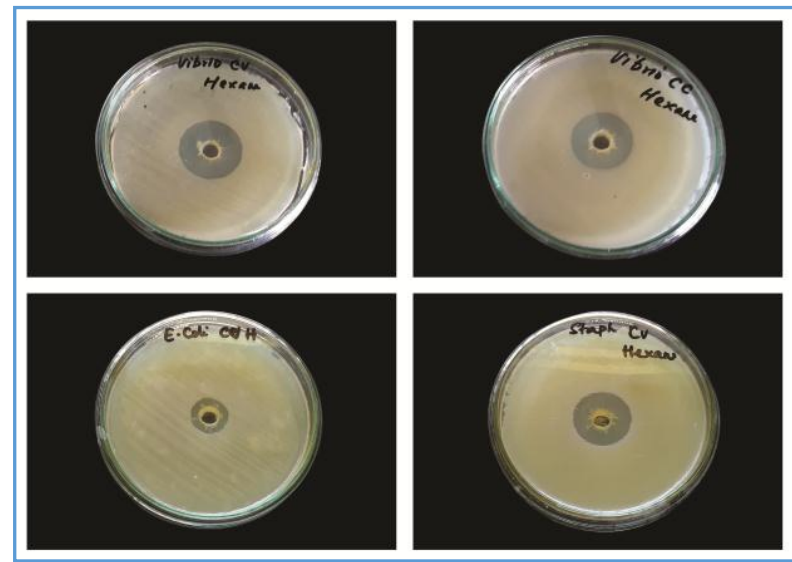

Figure 1. Hexane and Chloroform extract of Cinnamon Leaf Extract against Bacteria
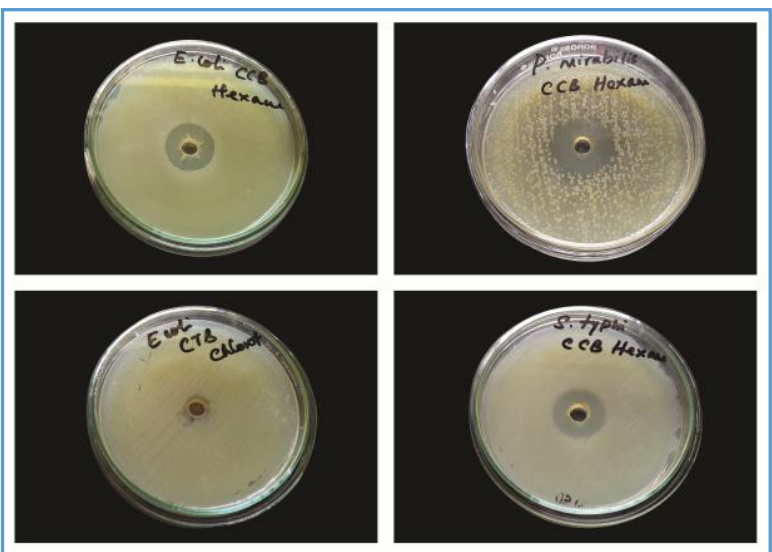

Figure 2. Hexane and Chloroform extract of Cinnamon bark extract against Bacteria

\section{DISCUSSION}

\section{Antibacterial Activity of Bark Extracts}

Antibacterial activity of bark extracts of four cinnamon species against twelve pathogenic bacteria is summarised in Table 1. Bark extracts were shown to be more efficient than leaf extract in inhibiting the tested organisms. Most of the bark extracts were potent enough to inhibit the growth of both Gram-positive and Gram-negative bacteria. Stenotrophomonas maltophilia is an emerging multidrugresistant global opportunistic pathogen. It causes nosocomial and community-acquired infections in immune-compromised individuals. ${ }^{8}$ Present study reveals that Stenotrophomonas maltophilia was inhibited by all of the tested bark extracts,

except methanol extract of C. cassia and C. camphora. The diameter of zone of inhibition (ZOI) towards sensitive extracts ranged from $16-51 \mathrm{~mm}$. S. maltophilia was found to be most sensitive among the tested organisms. Studies showed that cinnamon essential oil can inhibit the pathogens causing respiratory infections including S. maltophilia. ${ }^{9}$ To the best of our knowledge, this study is the first report on the antibacterial activity of solvent extracts of four cinnamon species against S. maltophilia. Vibrio cholera, a potent and important enteric pathogen was found to be inhibited by hexane extract of both C. verum and C. cassia (ZOI 30 and 28 $\mathrm{mm}$ ). Enterotoxin secreted by V. cholerae was an important virulence factor of the organism, which was responsible for a fatal secretory diarrhoea called cholera. All the bacteria, analysed in the antimicrobial activity testing were inhibited by C. verum and C. cassia hexane extract except Enterobacter hormaechei, which showed resistance to $\mathrm{C}$. cassia hexane extract. The genera Escherichia, Klebsiella, Enterobacter (collectively called coliform bacilli) and Proteus are members of normal intestinal flora; also they can act as an opportunistic pathogen. They can cause nosocomial infections of urinary tract, surgical sites, blood stream and pneumonia. P. mirabilis is the most frequent cause of infection related to kidney stones. K. pneumoniae causes severe pneumonia. ${ }^{10} \mathrm{~S}$. aureus (causative agent of superficial skin infections such as boils, furuncles, styes and impetigo in humans) was highly resistant to most of the extracts. But it showed good zone of inhibition with $\mathrm{C}$. verum hexane extract $(28 \mathrm{~mm})$. These results indicate that bark of both $C$. verum and $\mathrm{C}$. cassia serve as an excellent anti-bacterial agent and can inhibit a range of bacteria. All the bacteria tested were clinically significant organisms. Most of them are enteric pathogens. They are E. coli, K. pneumoniae and E. hormaechei, P. mirabilis, S. typhi, S. paratyphi, V. cholerae, S. boydii and $\mathrm{L}$. monocytogenes. As the cinnamon is used in routine culinary purposes and is able to inhibit these enteric pathogens increases the relevance of the present study which highlights the nutraceutical properties of cinnamon.

\section{Antibacterial Activity of Leaf Extracts}

Antibacterial activity of leaf extracts of four cinnamon species against twelve pathogenic bacteria is summarised in Table 2 . The diameter of zone of inhibition of leaf extracts was less compared to bark extracts indicating that leaf extracts are less sensitive compared to bark extracts. But P. aeruginosa showed the ZOI of $30 \mathrm{~mm}$ with $\mathrm{C}$. verum chloroform extract. $\mathrm{P}$. aeruginosa is an opportunistic pathogen, a major threat to hospitalised patients those who were affected with cancer and burns. ${ }^{11} \mathrm{~V}$. cholerae showed the ZOI of 29,30 and $31 \mathrm{~mm}$ with C. tamala hexane extract, C. camphora hexane and chloroform extract and S. maltophilia had a ZOI of $29 \mathrm{~mm}$ with C. cassia chloroform extract respectively. The ZOI of other extracts with the twelve bacteria tested were in the range of 11.5 - $26 \mathrm{~mm}$. Earlier work using agar well diffusion method suggested that leaf oleoresin can inhibit Penicillium citrinum, leaf volatile oil and oleoresin have shown better results in comparison with bark volatile oil, oleoresin and commercial bactericide. ${ }^{12}$ Study of essential oil from leaves of Cinnamomum osmophloeum oils had an excellent inhibitory effect on bacteria. ${ }^{13}$ Results from the antifungal tests conducted demonstrated that cinnamaldehyde possessed the strongest antifungal activity compared to the other constituents of the essential oils. ${ }^{14}$

\section{Determination of Minimum Inhibitory Concentration (MIC)}

The extracts showing a ZOI greater than $15 \mathrm{~mm}$ were selected for determination of minimum inhibitory concentration. The MIC values of different extracts against test bacteria are listed in Table 3. C. cassia hexane extract showed a least MIC value with S. maltophilia $(3.13 \mathrm{mg} / \mathrm{mL})$. Most of the bark extracts and leaf extracts showed the MIC in the range of $12.5-6.25$ $\mathrm{mg} / \mathrm{mL}$. Interestingly, $\mathrm{V}$. cholera a potent pathogen was inhibited by C. camphora leaf chloroform extract at the MIC of $3.13 \mathrm{mg} / \mathrm{mL}$. The highest MIC was obtained for E. coli with C. cassia bark hexane extract $(25 \mathrm{mg} / \mathrm{mL})$. Previous studies reported that in comparison with crude extracts, essential oil of cinnamon have lower MIC value. This could be due to the fact that crude extracts contain both volatile and non-volatile 
contents, but essential oil contain higher levels of volatile components such as cinnamaldehyde than crude extract. ${ }^{15}$ In another study conducted revealed that both essential oil and pure cinnamaldehyde have an equal potential in inhibiting Gram-positive, Gram-negative bacteria, yeasts and molds. ${ }^{16}$

\section{Comparison of Antibacterial Potential of Extracts with Antibiotics}

Antibiotic sensitivity pattern of Gram-positive, Gram-negative and Pseudomonas species were checked and was compared with some selected extracts which showed good antibacterial activity. From the results, it was demonstrated that the antibacterial activity of tested extracts was on par with the antibiotics. Even though the extracts were in crude form when compared to highly purified antibiotics, they showed a diameter of zone of inhibition similar to the antibiotics. S. maltophilia was found to be sensitive to all the tested antibiotics. ${ }^{17}$ Present work also showed that S. maltophilia was inhibited by many of the tested extracts giving highest diameter of zone of inhibition and statistically significant ( $\mathrm{p}$ 0.005). E. coli tested in the study was resistant to Augmentin, which is in accord with those found in the studies. ${ }^{18}$ Majority of the organisms used in the present study comes under the family enterobacteriaceae. From the results, it is shown that all of them are susceptible to Imipenem, a carbapenem. Because these organisms have the ability to produce $\beta$ lactamase enzyme, which give resistance to penicillin and cephalosporin. So carbapenems become the drug of choice. ${ }^{19}$

\section{CONCLUSION}

From the present study, it could be concluded that selected extracts of cinnamon species have a remarkable potential in inhibiting the growth of major pathogenic bacteria. Activity of the extract was comparable with the activity of the antibiotics in inhibiting the pathogens. Though both bark and leaf extracts of cinnamon species showed antimicrobial property, bark extracts are found to be better than leaf extracts. Further purification of the extracts from their crude form would definitely enhance their antimicrobial efficiency. Incorporation of these extracts in purified form adds a new dimension in food preservation as a very safe alternative with a very appealing odour and a very high consumer preference. To our knowledge, this is the first report on the comparison of antibacterial property of extracts from different Cinnamomum sp. and also the comparison between leaf and bark extracts on their antibacterial activity.

\section{ACKNOWLEDGEMENTS}

The authors thank the Director, ICAR- Indian Institute of Spices Research for providing facilities. The authors express their sincere thanks to the Principal, Co-operative Institute of Health Sciences, Thalassery, Kerala for providing lab facilities for this research work.

\section{REFERENCES}

[1] Brackman G, Defoirdt T, Miyamoto C, et al. cinnamaldehyde and cinnamaldehyde derivatives reduce virulence in vibrio spp. by decreasing the DNAbinding activity of the quorum sensing response regulator LuxR. BMC Microbiol 2008;8:149.

[2] Brooke JS. Stenotrophomonas maltophilia: an emerging global opportunistic pathogen. Clin Microbiol Rev 2012;25(1):2-41.
[3] Brul S, Coote P. Preservative agents in foods. Mode of action and microbial resistance mechanisms. Int $\mathrm{J}$ Food Microbiol 1999;50(1-2):1-17.

[4] Chang ST, Chen PF, Chang SC. Antibacterial activity of leaf essential oils and their constituents from cinnamomum osmophloeum. J Ethnopharmacol 2001;77(1):123-7.

[5] Fabio A, Cermelli C, Fabio G, et al. Screening of the antibacterial effects of a variety of essential oils on microorganisms responsible for respiratory infections. Phytother Res 2007;21(4):374-7.

[6] Gould GW. Industry perspective on the use of natural antimicrobials and inhibitors for food application. J Food Prot 1996;59(13):82-6.

[7] Gupta C, Garg AP, Uniyal RC, et al. Comparative analysis of the antimicrobial activity of cinnamon oil and cinnamon extract on some food-borne microbes. Afr J Microbiol Res 2008;2(9):247-51.

[8] Guentzel MN. Escherichia, klebsiella, enterobacter, serratia, citrobacter, and proteus. Chap- 26. In: Baron S, ed. Medical microbiology. 4th edn. Galveston (TX): University of Texas Medical Branch at Galveston 1996.

[9] Guzek A, Tomaszewski D, Rybicki Z, et al. Comparison of in vitro efficacy of ertapenem, imipenem and meropenem in the infections caused by the enterobacteriaceae strains family. Anaesthesiol Intensive Ther 2013;45(2):67-72.

[10] Iglewski BH. Pseudomonas. Chap- 27. In: Baron S, ed. Medical microbiology. 4th edn. Galveston (TX): University of Texas Medical Branch at Galveston 1996.

[11] Ooi LSM, Li Y, Kam SL, et al. Antimicrobial activities of cinnamon oil and cinnamaldehyde from the Chinese medicinal herb cinnamomum cassia Blume. Am J Chin Med 2006;34(3):511-22.

[12] Pattnaik S, Padhan DK, Jana GK. Evaluation of cinnamon oil, peppermint oil, cardamom oil \& orange oil as antimicrobial agents. J Pharm Res 2010;3(2):414-6.

[13] Ravindran PN, Nirmal-Babu K, Shylaja M. Cinnamon and cassia: the genus cinnamomum. Boca Raton, FL, USA: CRC Press 2004.

[14] Sabir S, Anjum AA, Ijaz T, et al. Isolation and antibiotic susceptibility of E. coli from urinary tract infections in a tertiary care hospital. Pak J Med Sci 2014;30(2):38992.

[15] Shan B, Cai YZ, Brooks JD, et al. Antibacterial properties and major bioactive components of cinnamon stick (Cinnamomum burmannii): activity against foodborne pathogenic bacteria. J Agric Food Chem 2007;55(14):5484-90.

[16] Singh G, Maurya S, DeLampasona MP, et al. A comparison of chemical, antioxidant and antimicrobial studies of cinnamon leaf and bark volatile oils, oleoresins and their constituents. Food Chem Toxicol 2007;45(9):1650-61.

[17] Vergis J, Gokulakrishnan P, Agarwal RK, et al. Essential oils as natural food antimicrobial agents: a review. Crit Rev Food Sci Nutr 2015;55(10):1320-3. 
[18] $\mathrm{Vu} \mathrm{TT}$, Kim $\mathrm{H}$, Tran VK, et al. In vitro antibacterial activity of selected medicinal plants traditionally used in Vietnam against human pathogenic bacteria. BMC Complement Altern Med 2016;16(1):32.
[19] Wang SY, Chen PF, Chang ST. Antifungal activities of essential oils and their constituents from indigenous cinnamon (Cinnamomum osmophloeum) leaves against wood decay fungi. Bioresour Technol 2005;96(7):813-8. 